\title{
The association of parameters of body composition and laboratory markers with the severity of hypertriglyceridemia- induced pancreatitis
}

Lifang Chen ${ }^{1}$, Yingbao Huang ${ }^{1}$, Huajun Yu ${ }^{2}$ Kehua Pan ${ }^{1}$, Zhao Zhang ${ }^{1}$, Yi Man ${ }^{1}$ and Dingyuan $\mathrm{Hu}^{3^{*}}$ (I)

\begin{abstract}
Background: Hypertriglyceridemia has arisen as the third leading cause of acute pancreatitis. This study aimed at exploring the association between the severity of hypertriglyceridemia-induced pancreatitis (HTGP) and computed tomography (CT)-based body composition parameters and laboratory markers.

Methods: Laboratory and clinical parameters were collected from 242 patients with HTGP between 2017 and 2020. Severity of HTGP was evaluated by original or modified CT severity index. Body composition parameters such as area and radiodensity of muscle, subcutaneous adipose tissue and visceral adipose tissue were calculated by CT at the level of third lumbar vertebra. Parameters were compared between mild and moderately severe to severe HTGP. Uni-variate and multi-variate Logistic regression analyses were employed to assess the risk factors of the severity of HTGP.

Results: Seventy patients (28.9\%) presented with mild HTGP. Body mass index, waist circumference and all CTbased body composition parameters differed between male and female patients. None was associated with the severity of HTGP, neither in males nor in females. Receiver operating characteristic curves showed that areas under the curves of apolipoprotein A-I and albumin to predict the severity of HTGP were 0.786 and 0.759 , respectively (all $P<0.001)$. Uni-variate and further multi-variate Logistic regression analysis confirmed that low serum albumin $(<35$ $\mathrm{g} / \mathrm{L}, P=0.004, \mathrm{OR}=3.362,95 \% \mathrm{Cl}=1.492-8.823)$ and apolipoprotein $\mathrm{A}-\mathrm{I}(<1.1 \mathrm{~g} / \mathrm{L}, P<0.001, \mathrm{OR}=5.126,95 \% \mathrm{Cl}=$ 2.348-11.195), as well as high C-reactive protein ( $>90 \mathrm{mg} / \mathrm{L}, P=0.005, \mathrm{OR}=3.061,95 \% \mathrm{Cl}=1.407-6.659)$ and lipase $(P=0.033, \mathrm{OR}=2.283,95 \% \mathrm{Cl}=1.070-4.873)$ were risk factors of moderately severe to severe HTGP. Levels of albumin, apolipoprotein A-I, C-reactive protein and lipase were also associated with the length of hospital stay (all $P<0.05)$. Besides, low serum albumin, low-density lipoprotein cholesterol and high radiodensity of subcutaneous adipose tissue were significant risk factors of pancreatic necrosis in patients with HTGP (all $P<0.05$ ).

(Continued on next page)
\end{abstract}

\footnotetext{
* Correspondence: dingyuan.hu@wzhealth.com

${ }^{3}$ Department of Gastroenterology, the Second Affiliated Hospital of Wenzhou

Medical University, Xue Yuan Xi Lu 109, Lucheng District, Wenzhou 325027,

China

Full list of author information is available at the end of the article
}

(C) The Author(s). 2021 Open Access This article is licensed under a Creative Commons Attribution 4.0 International License, which permits use, sharing, adaptation, distribution and reproduction in any medium or format, as long as you give appropriate credit to the original author(s) and the source, provide a link to the Creative Commons licence, and indicate if changes were made. The images or other third party material in this article are included in the article's Creative Commons licence, unless indicated otherwise in a credit line to the material. If material is not included in the article's Creative Commons licence and your intended use is not permitted by statutory regulation or exceeds the permitted use, you will need to obtain permission directly from the copyright holder. To view a copy of this licence, visit http://creativecommons.org/licenses/by/4.0/ The Creative Commons Public Domain Dedication waiver (http://creativecommons.org/publicdomain/zero/1.0/) applies to the data made available in this article, unless otherwise stated in a credit line to the data. 
(Continued from previous page)

Conclusions: Low serum albumin and apolipoprotein A-I, and high C-reactive protein and lipase upon admission were associated with a more severe type of HTGP and longer hospital stay for these patients. Albumin and apolipoprotein A-I may serve as novel biomarkers for the severity of HTGP. However, none of the body composition parameters was associated with the severity of HTGP.

Keywords: Hypertriglyceridemia-induced pancreatitis, Computed tomography, Body composition, Albumin, Severity, Apolipoprotein A-I, Pancreatic necrosis

\section{Background}

Acute pancreatitis (AP) is the inflammation of the pancreas with unpredictable clinical outcome. Although most acute pancreatitis cases are mild and can be cured successfully, some can lead to local complications, systematic inflammatory response syndrome and organ failure, which are associated with a substantial mortality. Gallstones and alcohol abuse are currently the most frequent causes of AP. Notably, the proportion of hypertriglyceridemia (HTG)-induced pancreatitis (HTGP) in AP is increasing during the decades [1], and now ranked as the third leading cause for AP [2, 3]. HTGP accounts for approximately $9 \%$ of all cases and as much as $56 \%$ of AP cases during pregnancy [4]. It is associated with a similar clinical course as other forms of AP, only distinguished by initially being HTG [5]. Although debated, HTGP tends to be more severe than AP caused by other etiological factors [4]. It has been postulated that HTGP may specifically benefit from plasmapheresis [4], which is the most direct and life-saving therapy in severe episodes.

HTG is defined as fasting plasma triglycerides (TGs) over $1.7 \mathrm{mmol} / \mathrm{L}$ or non-fasting TGs over $2.0 \mathrm{mmol} / \mathrm{L}$ [6]. It is classified as moderate HTG with TGs level ranging from $1.7-5.6 \mathrm{mmol} / \mathrm{L}$, or severe HTG when TGs are $\geq 5.6 \mathrm{mmol} / \mathrm{L}$. In patients with moderate HTG, identification and corresponding management of secondary factors such as Diabetes Mellitus, hypothyroidism and chronic liver disease is highly recommended [7]. Statin therapy should be initiated in those with persistent HTG in order to reduce atherosclerotic cardiovascular risk when secondary factors have been addressed. In patients with severe HTG, chylomicrons begin to be involved in the carriage of TGs, while their increase in plasma confers a higher risk of acute pancreatitis [8]. This risk increases with the degree of elevation of TGs and pancreatitis typically occurs when TGs are over 11.3 $\mathrm{mmol} / \mathrm{L}$. Therefore, prevention of pancreatitis is a key target for the management of severe HTG. To reduce the risk of HTGP, further treatments for severe HTG include a very-low-fat diet, restricted carbohydrate and alcohol intake, fibrates and Omega-3 fatty acids [8, 9]. Most patients with severe HTGs have a genetic component. For instance, familial chylomicronemia syndrome
(FCS) is a rare monogenic disorder responsible for extremely high levels of plasma TGs, putting patients at a very high risk for acute pancreatitis [10].

The precise pathophysiology underlying HTGP remain unclear. However, it is generally believed that the deposition of free fatty acids hydrolyzed by pancreatic lipase from triglyceride (TG) drives the occurrence of the disease [11]. The fatty acids can be bound to serum albumin, whereas the exceeded free fatty acids exert a detergent-like role and attacks platelets, vascular endothelium, and acinar cells. Although some studies have recognized the effect of albumin levels on severity and organ failure in AP, it has not been included as a risk factor of AP in most studies and in clinical practice. To our knowledge, there are no studies investigating the association of serum albumin with HTGP, despite that serum albumin might be more closely linked to the deposition of free fatty acids and the severity of HTGP.

Since the prognosis and clinical intervention of AP differs largely in mild AP and severe AP, the early prediction of the severity in AP has been a great concern and research focus for clinicians. Predictive parameters, including clinical, laboratory and radiological markers, as well as various scoring systems, have been proposed. Current guidelines recommend that persistent systemic inflammatory response syndrome or organ failure for at least $48 \mathrm{~h}$ is predictive of the severity of AP [12]. Other recognized risk factors for development of severe AP include elevated hematocrit, blood urea nitrogen and creatinine and body mass index [13, 14]. Several scoring systems, such as Acute Physiology and Chronic Health Evaluation II (APACHE II), the Bedside Index for Severity in Acute Pancreatitis (BISAP), and Ranson's Criteria have proven their correlation with the severity of AP, but their clinical utilities are still limited due to the low predictive values $[15,16]$. Computed tomography (CT) on admission has a similar predictive accuracy for the severity of AP as clinical scoring systems [17]. Although not recommended by the guidelines [12], abdominal CT upon admission is often conducted in AP in real-world practice, especially in the emergent situation to exclude differential diagnoses. Contrast-enhanced CT is advantageous to delineate pancreatic or peripancreatic fluid collections and necrosis. It is the most applied method in 
the clinic to re-evaluate the severity of cases in potential deterioration.

Recent studies have suggested that the severity of AP is also linked to some radiological parameters describing body composition [18]. Larger peripancreatic volume of visceral adipose tissue (VAT) was found associated with severe AP [19] and high visceral fat with low skeletal muscle volume strongly correlated with AP severity [20]. A recent systematic review, which included 11 studies, concluded that VAT is an important prognostic indicator for the severity of AP and may be incorporated into the prognostic scoring systems of AP [21]. Nevertheless, muscle radiodensity, rather than VAT and subcutaneous adipose tissue (SAT), correlated with severe acute pancreatitis [22]. Notably, by stratifying AP into HTGP and non-HTGP, it was revealed that VAT and VAT/SAT were valuable factors for predicting the severity in HTGP, but not in non-HTGP [23].

With a focus on HTGP, a subgroup of AP with rising incidence, this study aimed at exploring body composition parameters and clinical risk factors for the severity of HTGP, which may help predict the prognosis of HTGP.

\section{Methods}

\section{Patients}

A total of 242 hospitalized patients with HTGP from the First Affiliated Hospital of Wenzhou Medical University between July 2017 and August 2020 were retrospectively studied. The diagnosis of AP was established according to the Revised Atlanta Definitions of AP [24], when two of the following three characteristics were met: (1) the symptoms of abdominal pain were consistent with AP, (2) the levels of amylase and/or lipase were at least 3 times above the upper limit of the normal, and (3) abdominal imaging was consistent with changes in AP. HTGP was considered in AP patients when the level of serum TGs was (1) over $11.3 \mathrm{mmol} / \mathrm{L}$; (2) between 5.65 $\mathrm{mmol} / \mathrm{L}$ and $11.3 \mathrm{mmol} / \mathrm{L}$, milky serum, with no other etiology of AP; (3) not tested, but the patient, without any known etiology, had previously been diagnosed as HTGP. The inclusion criteria of patients in this study were (1) the diagnosis of HTGP was established; (2) abdominal CT scanning $72 \mathrm{~h}$ before the occurrence of symptom; exclusion criteria were (1) poor CT imaging of the abdomen; (2) indication of biliary, alcoholic, autoimmune, drug-induced or pancreatic tumor-related etiology of AP; (3) pregnancy. The study protocol was approved by the ethics committee of the First Affiliated Hospital of Wenzhou Medical University (KY2019-011). Participant informed consent was waived given the retrospective study design.

Contrast-enhanced CT scannings of abdomen were performed in 177 (73.1\%) of the studied patients when deterioration of the disease occurred during the course of the disease. The severity of HTGP was evaluated by modified CT severity index (MCTSI) if contrastenhanced CT scanning had been conducted, otherwise by the CT severity index based on unenhanced CT scanning.

Clinical parameters of each patient were retrieved from the Electronic Health Record System, including sex, gender, body mass index, length of hospital stay, and C-reactive protein (CRP), serum albumin, amylase, total cholesterol, low-density lipoprotein cholesterol (LDL-C), high-density lipoprotein cholesterol (HDL-C), apolipoprotein A-I (apoA-I), apolipoprotein B (apoB) and lipoprotein upon the admission (Table 1). CRP was determined by turbidimetric inhibition immunoassay, while all other plasma parameters were determined by Siemens ADVIA 2400 automatic biochemical analyzer. The levels of CRP, albumin and TGs were categorized as high and low with the cutoff of $90 \mathrm{mg} / \mathrm{L}, 35 \mathrm{~g} / \mathrm{L}$ and $22.4 \mathrm{mmol} / \mathrm{L}$ [25], respectively. APACHE II, BISAP, Ranson and Marshall scorings of the patients were calculated when possible.

\section{CT scanning and body composition parameters}

CT scanning was performed by 64-slice spiral CT scanner (Lightspeed VCT, GE healthcare, USA) or Aquilion ONE 320 Slice CT scanner (Toshiba, Japan). The scanning covered the whole abdomen. The slice thickness was $0.625 \mathrm{~mm}$ for 64-slice spiral CT scanner (pitch 0.984 , single-turn spiral time $0.5 \mathrm{~s}, 100 \mathrm{kV}, 500 \mathrm{~mA}$ ) and $0.5 \mathrm{~mm}$ for the 320 Slice CT scanner (single-turn spiral time $0.5 \mathrm{~s}, 100 \mathrm{kV}, 300 \mathrm{~mA}$ ). For contrast-enhanced CT, an auto-injector was used to inject $60 \mathrm{~mL}$ of non-ionic contrast agent (iopromide $300 \mathrm{mgI} / \mathrm{mL}$ ) and $30 \mathrm{~mL}$ of saline at a speed of $4.0 \mathrm{~mL} / \mathrm{s}$, and the scanning was triggered intelligently by monitoring of the abdominal aorta, the arterial phase was delayed for 30-35 s, and the portal phase was delayed for $60-70 \mathrm{~s}$. The imaging data were transferred to the post-processing workstation (Version 4.5, GE healthcare).

Body composition parameters were measured based on the non-enhanced CT scanning. Muscle and adipose tissue at the level of third lumbar vertebra (L3) with supine position were analyzed by Image J software [26]. A range of -29 to 150 Hounsfield units (HU) was set to highlight muscle, a range of -190 to $-30 \mathrm{HU}$ was set to highlight SAT, and -150 to $50 \mathrm{HU}$ for VAT. The area and density of the region of interest (ROI) were calculated automatically. Waist circumference was measured at the umbilical plane. CT measurements were performed by 2 experienced radiologists blinded to the clinical information. Re-measurement took place when disagreement of the measurements occurred. 
Table 1 Comparisons of laboratory parameters and clinical data in patients with mild and moderately severe to severe hypertriglyceridemia-induced pancreatitis

\begin{tabular}{|c|c|c|c|c|c|}
\hline Variables & HTGP & Mild HTGP & Moderately severe to Severe HTGP & $P$ values & Missing values \\
\hline Sex & & & & 0.141 & \\
\hline Male & 193 & $60(85.7)$ & $133(77.3)$ & & \\
\hline Female & 49 & $10(14.3)$ & $39(22.7)$ & & \\
\hline Age (years) & $40(34-47)$ & $42(35-49)$ & $39(33-46)$ & 0.101 & \\
\hline CRP (mg/L) & & & & $<0.001$ & 21 \\
\hline$<90$ & 91 & $43(69.4)$ & $48(30.2)$ & & \\
\hline$\geq 90$ & 130 & 19 (30.6) & $111(69.8)$ & & \\
\hline Albumin (g/L) & $36.54 \pm 6.56$ & $40.38 \pm 4.89$ & $34.98 \pm 6.52$ & $<0.001$ & \\
\hline$<35$ & 103 & $11(15.7)$ & $92(53.5)$ & $<0.001$ & \\
\hline$\geq 35$ & 139 & $59(84.3)$ & $80(46.5)$ & & \\
\hline Triglyceride (mmol/L) & $12.74(8.18-25.12)$ & $10.64(6.69-21.50)$ & $13.34(9.45-26.10)$ & 0.008 & 12 \\
\hline High $(<22.4 \mathrm{mmol} / \mathrm{L})$ & 163 & $50(76.9)$ & $113(68.5)$ & 0.205 & \\
\hline Very high ( $\geq 22.4 \mathrm{mmol} / \mathrm{L})$ & 67 & $15(23.1)$ & $52(31.5)$ & & \\
\hline Amylase (U/L) & $121(67-269)$ & $90(51-216)$ & $133(73-314)$ & 0.027 & \\
\hline Lipase (U/L) & $234(112-612)$ & $151(84-404)$ & $263(126-664)$ & 0.003 & 13 \\
\hline Total cholesterol (mmol/L) & $8.42(6.31-12.19)$ & $7.24(5.95-10.27)$ & $9.11(6.53-13.14)$ & 0.006 & \\
\hline $\mathrm{HDL}-\mathrm{C}(\mathrm{mmol} / \mathrm{L})$ & $0.60(0.46-0.79)$ & $0.76(0.62-0.87)$ & $0.56(0.43-0.70)$ & $<0.001$ & 1 \\
\hline LDL-C (mmol/L) & $2.06(1.59-1.92)$ & $1.96(1.57-2.46)$ & $2.13(1.59-2.97)$ & 0.231 & 1 \\
\hline Non-HDL-C (mmol/L) & $8.04(5.47-11.53)$ & $6.48(5.13-9.52)$ & $8.50(5.80-12.56)$ & 0.004 & 1 \\
\hline ApoA-I (g/L) & $0.84(0.67-1.09)$ & $1.10(0.84-1.30)$ & $0.78(0.66-0.97)$ & $<0.001$ & 7 \\
\hline ApoB (g/L) & $0.81(0.49-1.29)$ & $0.80(0.48-1.17)$ & $0.81(0.48-1.35)$ & 0.294 & 36 \\
\hline Lipoprotein (mg/L) & $48.5(26.8-115.3)$ & $48.0(30.0-86.0)$ & $49.0(23.0-129.0)$ & 0.830 & 8 \\
\hline Length of hospital stay (days) & $13(9-20)$ & $9(7-11.5)$ & $17(11-21)$ & $<0.001$ & \\
\hline$<14$ & 131 & $61(88.4)$ & $70(40.7)$ & $<0.001$ & \\
\hline$\geq 14$ & 110 & $8(11.6)$ & $102(59.3)$ & & \\
\hline
\end{tabular}

ApoA-I apolipoprotein A-I, ApoB apolipoprotein B, CRP C-reactive protein, $H D L-C$ high-density lipoprotein cholesterol, $H T G P$ hypertriglyceridemia-induced pancreatitis, $L D L-C$ low-density lipoprotein cholesterol

\section{Statistical analysis}

Parameters between mild and moderately severe to severe HTGP were compared. Comparisons of categorical data were performed using Chi-square test or Fisher's exact test. Continuous data were expressed as mean \pm standard deviation and compared by the student's $t$ test when normal distribution was justified, otherwise expressed as median (interquartile range) and compared by Mann Whitney U test. Uni-variate and multi-variate Logistic regression analyses were employed to assess the risk factors for the severity of HTGP. Variables with $P$ values less than 0.1 in univariate analysis were included for the multi-variate analysis with a backward method. To test the predictive capacity of the measured parameters, receiver operating characteristic (ROC) curves with corresponding areas under the curves (AUC) were calculated. A $P$-value of $<0.05$ was considered statistically significant. All the statistics were performed using SPSS 18.0 (IBM. SPSS Statistics for Windows, USA).

\section{Results}

Association of laboratory parameters and clinical data with the severity of HTGP

To investigate the association of the severity of HTGP with laboratory parameters and clinical data, comparisons were made between patients with mild HTGP and those with moderately severe to severe HTGP. Age and gender distribution showed no difference between the two groups (all $P>0.05$ ). In comparison, the levels of serum CRP, amylase and lipase, TGs, total cholesterol and non-HDL-C were significantly higher in patients with moderately severe to severe HTGP than those with mild HTGP (all $P<0.05$ ). However, concentrations of serum albumin (mean 34.98 vs. $40.38 \mathrm{~g} / \mathrm{L}$ ), HDL-C (median 0.56 vs. $0.76 \mathrm{mmol} / \mathrm{L}$ ), apoA-I (median 0.78 vs. 1.10 $\mathrm{g} / \mathrm{L}$ ) were significantly lower in the severe group (all $P<$ 0.001, Table 1).

ROC analysis depicted the AUCs of parameters for the prediction of HTGP severity (Fig. 1). ApoA-I $(P<0.001$, 


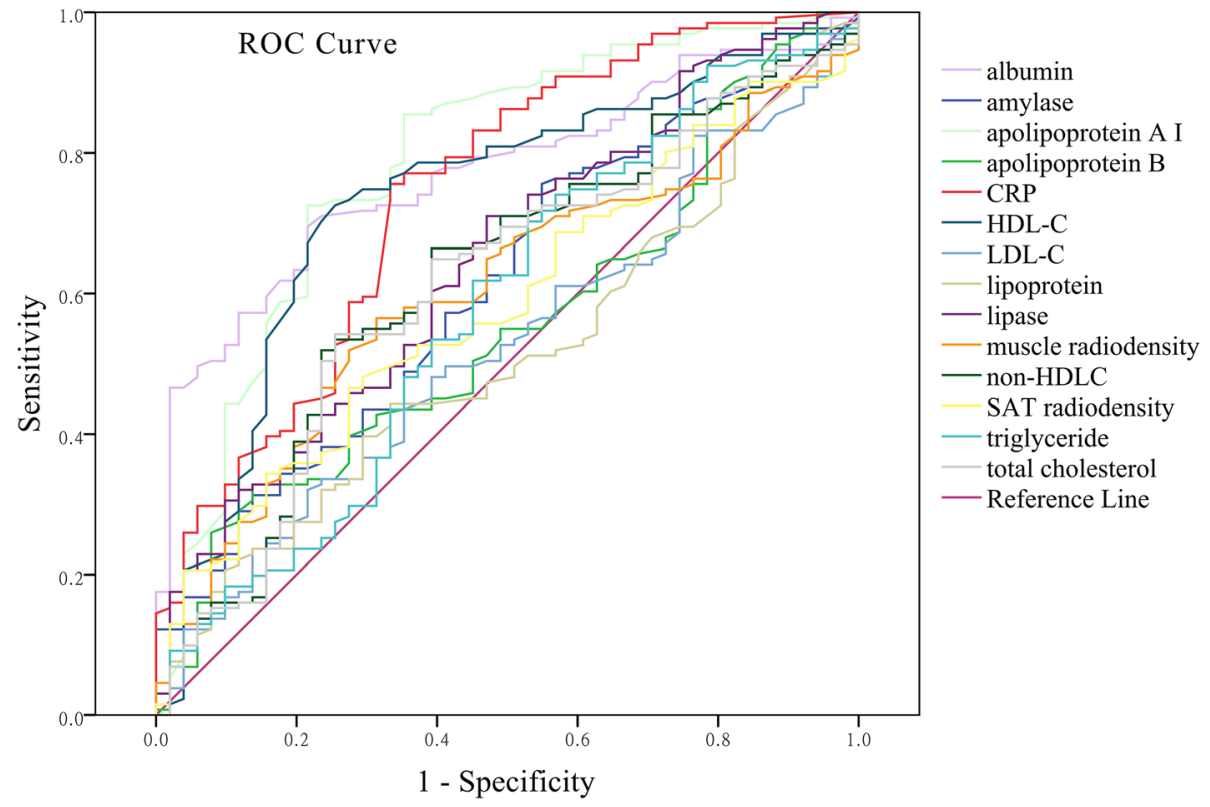

Fig. 1 Receiver operating characteristic curves of parameters for the predictive capacity for severity of HTGP. Apolipoprotein A-I $(P<0.001, A U C=$ 0.786), albumin $(P<0.001, A \cup C=0.759)$, $C$-reactive protein $(C R P)(P<0.001, A \cup C=0.743)$ and high-density lipoprotein cholesterol $(H D L-C)(P<$ 0.001 , AUC $=0.735$ ) showed the most statistical significance for predicting the severity of HTGP. AUC: areas under the curves; HTGP: hypertriglyceridemia-induced pancreatitis; LDL-C: low-density lipoprotein cholesterol; SAT: subcutaneous adipose tissue

AUC $=0.786)$, albumin $(P<0.001$, AUC $=0.759)$, CRP $(P<0.001, \mathrm{AUC}=0.743)$ and HDL-C $(P<0.001$, AUC $=$ $0.735)$ showed the most statistical significance for the prediction of HTGP severity. With a balanced cutoff of $1.1 \mathrm{~g} / \mathrm{L}$, apoA-I predicted the severity of HTGP with a sensitivity and specificity of 0.725 and 0.784 , respectively. A cutoff of $36.65 \mathrm{~g} / \mathrm{L}$ for albumin concentration achieved the sensitivity of 0.786 and specificity of 0.651 . With the cutoff of $35.0 \mathrm{~g} / \mathrm{L}$, the sensitivity and specificity were 0.843 and 0.535 , respectively. AUCs for other parameters were: muscle radiodensity $(0.625, P=0.004)$, SAT radiodensity $(0.580, P=0.066)$, triglyceride $(P=0.027$, AUC $=$ $0.596)$, amylase $(0.613, P=0.018)$, lipase $(0.645, P=$ $0.002)$, total cholesterol $(0.611, P=0.020)$, LDL-C $(0.524$, $P=0.617)$, non-HDL-C $(0.621, P=0.011)$, apoB $(0.553$, $P=0.264)$, lipoprotein $(0.512, P=0.797)$.

\section{Body composition parameters were divergent between male and female patients with pancreatitis}

Notably, apparent differences existed between male and female patients regarding all the body composition parameters studied in this study, including BMI, muscle area, muscle radiodensity, SAT area, SAT radiodensity, VAT area, VAT area/total adipose tissue area and waist circumference (all $P<0.05$ ). Therefore, stratified comparisons in either male or female patients were performed. The mean values of each parameter in male and female patients with HTGP are shown in Table 2. Consequently, the muscle radiodensity (mean 42.9 vs. 44.8
HU, $P=0.020$ ) was lower while SAT radiodensity (mean - 95.0 vs. $-97.7 \mathrm{HU}, P=0.009$ ) was higher in male patients with moderately severe or severe HTGP than in those with mild HTGP. For the subsequent analyses, all body composition parameters were categorized as high and low subgroups using corresponding median value in males or females as the cutoff. Uni-variate Logistic regression analysis indicated that none of the body composition parameters was associated with the severity of hypertriglyceridemia-induced pancreatitis, neither in male nor in female patients (all $P>0.05$, Table 3 ).

\section{Logistic regression analyses of risk factors for the severity of HTGP}

Uni-variate Logistic regression analysis was applied to explore parameters associated with the severity of HTGP. Consequently, age, lipase, amylase, CRP, albumin, total cholesterol, HDL-C, Non-HDL-C, apoA-I and muscle radiodensity were associated with the severity of HTGP (Table 4). High Pearson correlations were found between non-HDL-C and total cholesterol $(r=1.000$, $P<0.001)$, between lipase and amylase $(r=0.877, P<$ $0.001)$, and between apoA-I and HDL-C $(r=0.848, P<$ $0.001)$. Therefore, total cholesterol, amylase and HDL-C were removed from the following multi-variate Logistic analysis.

Multi-variate Logistic analysis confirmed that low albumin $(P=0.004, \mathrm{OR}=3.362,95 \% \mathrm{CI}=1.492-8.823)$ and apoA-I $(P<0.001, \mathrm{OR}=5.126,95 \% \mathrm{CI}=2.348-11.195)$ as 
Table 2 Comparisons of body composition parameters in patients with mild and moderately severe to severe hypertriglyceridemiainduced pancreatitis

\begin{tabular}{|c|c|c|c|c|}
\hline Variables & HTGP & Mild HTGP & Moderately severe to Severe HTGP & $P$ values \\
\hline \multicolumn{5}{|c|}{ Body mass index } \\
\hline Male & $26.3 \pm 3.3$ & $26.3 \pm 2.8$ & $26.3 \pm 3.5$ & 0.885 \\
\hline Female & $24.5 \pm 3.8$ & $24.4 \pm 5.8$ & $24.5 \pm 3.2$ & 0.912 \\
\hline \multicolumn{5}{|c|}{ Muscle area $\left(\mathrm{mm}^{2}\right)$} \\
\hline Male & $166.3 \pm 27.5$ & $165.4 \pm 27.6$ & $166.7 \pm 27.5$ & 0.763 \\
\hline Female & $110.1 \pm 16.6$ & $107.7 \pm 13.0$ & $110.7 \pm 17.5$ & 0.612 \\
\hline \multicolumn{5}{|c|}{ Muscle radiodensity (HU) } \\
\hline Male & $43.5 \pm 6.0$ & $44.8 \pm 4.8$ & $42.9 \pm 6.4$ & 0.020 \\
\hline Female & $39.6 \pm 5.8$ & $42.0 \pm 4.6$ & $39.0 \pm 6.0$ & 0.158 \\
\hline \multicolumn{5}{|c|}{ SAT area $\left(\mathrm{mm}^{2}\right)$} \\
\hline Male & $123.5 \pm 45.0$ & $1213 \pm 45.3$ & $124.5 \pm 49.3$ & 0.664 \\
\hline Female & $167.5 \pm 64.5$ & $157.6 \pm 80.0$ & $170.0 \pm 61.0$ & 0.592 \\
\hline \multicolumn{5}{|c|}{ SAT radiodensity (HU) } \\
\hline Male & $-95.8 \pm 7.7$ & $-97.7 \pm 5.7$ & $-95.0 \pm 8.4$ & 0.009 \\
\hline Female & $-99.8 \pm 5.4$ & $-101.2 \pm 3.9$ & $-99.5 \pm 5.7$ & 0.368 \\
\hline \multicolumn{5}{|c|}{ VAT area $\left(\mathrm{mm}^{2}\right)$} \\
\hline Male & $181.9 \pm 66.9$ & $187.9 \pm 63.7$ & $179.2 \pm 68.4$ & 0.405 \\
\hline Female & $122.8 \pm 52.6$ & $105.5 \pm 41.8$ & $127.2 \pm 54.6$ & 0.248 \\
\hline \multicolumn{5}{|c|}{ VAT area /TAT area } \\
\hline Male & $0.589 \pm 0.110$ & $0.604 \pm 0.088$ & $0.581 \pm 0.118$ & 0.187 \\
\hline Female & $0.418 \pm 0.091$ & $0.409 \pm 0.091$ & $0.421 \pm 0.092$ & 0.725 \\
\hline \multicolumn{5}{|c|}{ Waist circumference $(\mathrm{cm})$} \\
\hline Male & $90.1 \pm 8.6$ & $89.8 \pm 8.4$ & $90.2 \pm 8.77$ & 0.766 \\
\hline Female & $83.9 \pm 10.4$ & $82.4 \pm 7.7$ & $84.3 \pm 11.1$ & 0.613 \\
\hline
\end{tabular}

HTGP hypertriglyceridemia-induced pancreatitis, SAT subcutaneous adipose tissue, TAT total adipose tissue, VAT visceral adipose tissue

Table 3 Uni-variate Logistic regression analysis of body composition parameters associated with the severity of hypertriglyceridemia-induced pancreatitis in male and female patients

\begin{tabular}{llllll}
\hline Variables & Male & & & \multicolumn{2}{l}{ Female } \\
\cline { 2 - 3 } & P values & OR (95\%Cl) & & & OR (95\%Cl) \\
\hline Body mass index (> 26) & 0.618 & $1.168(0.634-2.154)$ & & 0.602 & $1.571(0.287-8.595)$ \\
Muscle area (>median) & 0.327 & $1.358(0.736-2.504)$ & & 0.438 & $1.750(0.426-7.190)$ \\
Muscle radiodensity (>median) & 0.070 & $0.565(0.304-1.049)$ & & 0.438 & $0.571(0.139-2.348)$ \\
SAT area (>median) & 0.327 & $1.358(0.736-2.504)$ & & 0.147 & $3.020(0.678-13.442)$ \\
SAT radiodensity (>median) & 0.110 & $1.652(0.892-3.060)$ & & 0.623 & $1.425(0.347-5.851)$ \\
VAT area (>median) & 0.377 & $0.759(0.412-1.399)$ & & 0.147 & $3.020(0.678-13.442)$ \\
VAT area/TAT area (>median) & 0.377 & $0.759(0.412-1.399)$ & & 0.438 & $1.750(0.426-7.190)$ \\
Waist circumference (>median) & 0.327 & $1.358(0.736-2.504)$ & & 0.942 & $1.053(0.262-4.224)$ \\
\hline
\end{tabular}

HTGP hypertriglyceridemia-induced pancreatitis, SAT subcutaneous adipose tissue, TAT total adipose tissue, VAT visceral adipose tissue 
Table 4 Logistic regression analysis of parameters associated with the severity of hypertriglyceridemia-induced pancreatitis

\begin{tabular}{|c|c|c|c|c|}
\hline \multirow[t]{2}{*}{ Variables } & \multicolumn{2}{|c|}{ Uni-variate analysis } & \multicolumn{2}{|c|}{ Multi-variate analysis } \\
\hline & $P$ values & OR $(95 \% \mathrm{Cl})$ & $P$ values & OR $(95 \% \mathrm{Cl})$ \\
\hline Age & 0.027 & $0.526(0.298-0.930)$ & 0.083 & $0.524(0.253-1.087)$ \\
\hline Sex & 0.144 & $0.568(0.266-1.214)$ & & \\
\hline Lipase & 0.017 & $2.050(1.134-3.704)$ & 0.033 & $2.283(1.070-4.873)$ \\
\hline Amylase & 0.040 & $1.808(1.028-3.179)$ & & \\
\hline $\mathrm{CRP}(>90 \mathrm{mg} / \mathrm{L})$ & $<0.001$ & $5.234(2.767-9.899)$ & 0.005 & $3.061(1.407-6.659)$ \\
\hline Albumin $(<35 \mathrm{~g} / \mathrm{L})$ & $<0.001$ & $6.168(3.033-12.546)$ & 0.004 & $3.362(1.492-8.823)$ \\
\hline Triglyceride ( $\geq 22.4 \mathrm{mmol} / \mathrm{L})$ & 0.207 & $1.534(0.790-2.979)$ & & \\
\hline Total cholesterol & 0.002 & $2.479(1.390-4.420)$ & & \\
\hline $\mathrm{HDL}-\mathrm{C}$ & $<0.001$ & $0.210(0.111-0.397)$ & & \\
\hline LDL-C & 0.124 & $1.553(0.886-2.720)$ & & \\
\hline Non-HDL-C & 0.002 & $2.512(1.408-4.482)$ & 0.170 & $1.724(0.739-3.749)$ \\
\hline ApoA-I $(<1.1 \mathrm{~g} / \mathrm{L})$ & $<0.001$ & $6.495(3.390-12.446)$ & $<0.001$ & $5.126(2.348-11.195)$ \\
\hline ApoB & 0.808 & $1.077(0.592-1.959)$ & & \\
\hline Lipoprotein & 0.885 & $1.043(0.591-1.838)$ & & \\
\hline
\end{tabular}

ApoA-I apolipoprotein A-I, ApoB apolipoprotein B, CRP C-reactive protein, HDL-C high-density lipoprotein cholesterol, LDL-C low-density lipoprotein cholesterol

well as high CRP $(P=0.005, \mathrm{OR}=3.061,95 \% \mathrm{CI}=1.407-$ 6.659) and lipase $(P=0.033, \mathrm{OR}=2.283,95 \% \mathrm{CI}=1.070-$ 4.873) worsened the severity of HTGP (Table 3 ).

\section{Analyses of risk factors for occurrence of pancreatic necrosis}

A total of 178 patients, comprising 37 female and 141 male patients, underwent enhanced CT scanning. Of them, 37 (6 women, 31 men) presented with pancreatic necrosis. By uni-variate Logistic regression analysis, the risk of pancreatic necrosis was shown to be associated with high levels of CRP and SAT radiodensity, and low levels of serum albumin, LDL-C, HDL-C, apoA-I and apoB (all $P<0.05$, Table 5). By multi-variate Logistic analysis, low serum albumin $(P=0.003, \quad \mathrm{OR}=4.154$, $95 \% \mathrm{CI}=1.633-10.564)$, low LDL-C $\quad(P=0.013$, OR = $0.306,95 \% \mathrm{CI}=0.120-0.778)$ and high $\mathrm{SAT}$ radiodensity
$(P=0.007, \quad \mathrm{OR}=3.592,95 \% \mathrm{CI}=1.417-9.106)$ remained to be significant risk factors of pancreatic necrosis in patients with HTGP (Table 5).

Association of albumin, apo A-I, CRP and lipase with the length of hospital stay and clinical scoring parameters for patients with HTGP

Since low albumin and apo A-I and high CRP and lipase were shown to be risk factors for severity of HTGP, their associations with the length of hospital stay and clinical severity scoring parameters were further studied. Low albumin and apo A-I, as well as high CRP and lipase were all associated with a longer hospital stay and higher Ranson scores (all $P<0.05$, Table 6). Specifically, HTGP patients with low serum albumin had a significantly longer hospital stay (median 18 days vs. 11 days, $P<0.001$ ) and higher proportion of hospital stay exceeding 2 weeks

Table $\mathbf{5}$ Logistic analysis of parameters associated with the risk of pancreatic necrosis in patients with hypertriglyceridemia-induced pancreatitis.

\begin{tabular}{|c|c|c|c|c|}
\hline \multirow[t]{2}{*}{ Variables } & \multicolumn{2}{|c|}{ Uni-variate analysis } & \multicolumn{2}{|c|}{ Multi-variate analysis } \\
\hline & $P$ values & OR $(95 \% \mathrm{Cl})$ & $P$ values & OR $(95 \% \mathrm{Cl})$ \\
\hline $\mathrm{CRP}(>90 \mathrm{mg} / \mathrm{L})$ & 0.014 & $3.069(1.254-7.513)$ & 0.385 & $1.650(0.534-5.103)$ \\
\hline Albumin $(<35 \mathrm{~g} / \mathrm{L})$ & $<0.001$ & 4.350 (1.952-9.691) & 0.003 & $4.154(1.633-10.564)$ \\
\hline LDL-C & 0.004 & $0.317(0.145-0.692)$ & 0.013 & $0.306(0.120-0.778)$ \\
\hline $\mathrm{HDL}-\mathrm{C}$ & 0.004 & $0.312(0.140-0.693)$ & 0.939 & $1.057(0.257-4.349)$ \\
\hline ApoA-I & 0.044 & $0.460(0.216-0.979)$ & 0.734 & $0.846(0.322-2.221)$ \\
\hline ApoB & $<0.050$ & $0.443(0.197-0.999)$ & 0.379 & $0.632(0.227-1.759)$ \\
\hline SAT radiodensity & $<0.001$ & $3.864(1.737-8.593)$ & 0.007 & 3.592 (1.417-9.106) \\
\hline
\end{tabular}

$\overline{A p o A-I}$ apolipoprotein A-I, $A p o B$ apolipoprotein B, CRP C-reactive protein, HDL-C high-density lipoprotein cholesterol, LDL-C low-density lipoprotein cholesterol, SAT subcutaneous adipose tissue 
Table 6 Association of albumin, apoA-I, CRP, and lipase with the length of hospital stay and clinical scoring parameters for patients with hypertriglyceridemia-induced pancreatitis

\begin{tabular}{|c|c|c|c|c|c|c|c|c|c|}
\hline \multirow[t]{2}{*}{ Variables } & \multicolumn{2}{|c|}{ Albumin (g/L) } & \multicolumn{2}{|c|}{ ApoA-I (g/L) } & \multicolumn{2}{|c|}{ CRP (mg/L) } & \multicolumn{2}{|c|}{ Lipase (U/L) } & \multirow{2}{*}{$\begin{array}{l}\text { Missing } \\
\text { value }\end{array}$} \\
\hline & $<35$ & $\geq 35$ & $<1.1$ & $\geq 1.1$ & $<90$ & $\geq 90$ & low & high & \\
\hline \multicolumn{10}{|c|}{ Length of hospital stay N (\%) } \\
\hline$<2$ weeks & $34(33.0)$ & $97(70.3)$ & $85(48)$ & $42(73.7)$ & $63(70.0)$ & $53(40.8)$ & $74(64.9)$ & $46(40.0)$ & 1 \\
\hline$\geq 2$ weeks & $69(67.0)$ & $41(29.7)$ & $92(52)$ & $15(26.3)$ & $27(30.0)$ & $77(59.2)$ & $40(35.1)$ & $69(60.0)$ & \\
\hline$P$ values & \multicolumn{2}{|l|}{$<0.001$} & \multicolumn{2}{|l|}{$<0.001$} & \multicolumn{2}{|l|}{$<0.001$} & \multicolumn{2}{|l|}{$<0.001$} & \\
\hline OR $(95 \% \mathrm{Cl})$ & \multicolumn{2}{|c|}{$4.801(2.771-8.318)$} & \multicolumn{2}{|c|}{$3.031(1.568-5.859)$} & \multicolumn{2}{|c|}{$3.390(1.916-5.998)$} & \multicolumn{2}{|c|}{$2.775(1.624-4.742)$} & \\
\hline \multicolumn{10}{|c|}{ APACHE II N (\%) } \\
\hline$<8$ & $61(64.2)$ & $94(83.2)$ & $113(70.6)$ & $37(86.0)$ & $58(80.6)$ & $81(68.1)$ & $78(82.1)$ & $71(66.4)$ & 34 \\
\hline$\geq 8$ & $34(35.8)$ & 19 (16.8) & $47(29.4)$ & $6(14.0)$ & $14(19.4)$ & $38(31.9)$ & $17(17.9)$ & $36(33.6)$ & \\
\hline$P$ values & \multicolumn{2}{|l|}{0.002} & \multicolumn{2}{|l|}{0.041} & \multicolumn{2}{|l|}{0.060} & \multicolumn{2}{|l|}{0.011} & \\
\hline OR $(95 \% \mathrm{Cl})$ & \multicolumn{2}{|c|}{$2.758(1.443-5.268)$} & \multicolumn{2}{|c|}{$2.565(1.015-6.483)$} & \multicolumn{2}{|c|}{$1.944(0.966-3.911)$} & \multicolumn{2}{|c|}{$2.326(1.202-4.503)$} & \\
\hline \multicolumn{10}{|l|}{ BISAP N (\%) } \\
\hline$<3$ & 85 (91.4) & $107(100)$ & $150(94.9)$ & $39(100)$ & 69 (98.6) & $106(93.8)$ & 88 (96.6) & $101(95.3)$ & 42 \\
\hline$\geq 3$ & $8(8.6)$ & 0 & $8(5.1)$ & 0 & $1(1.4)$ & $7(6.2)$ & $3(3.4)$ & $5(4.7)$ & \\
\hline$P$ values & \multicolumn{2}{|l|}{0.002} & \multicolumn{2}{|l|}{0.360} & \multicolumn{2}{|l|}{0.125} & \multicolumn{2}{|l|}{0.637} & \\
\hline OR (95\%Cl) & \multicolumn{2}{|c|}{$0.443(0.378-0.519)$} & \multicolumn{2}{|c|}{$0.794(0.738-0.853)$} & $4.577(0.5$ & 37.852) & $1.419(0.3$ & $6.111)$ & \\
\hline Ranson N (\%) & & & & & & & & & \\
\hline$<3$ & $38(40.9)$ & $72(67.3)$ & $78(49.7)$ & $30(75.0)$ & $48(67.6)$ & $48(42.9)$ & $63(71.6)$ & $43(40.2)$ & 42 \\
\hline$\geq 3$ & $55(59.1)$ & $35(32.7)$ & $79(50.3)$ & $10(25.0)$ & $23(32.4)$ & $64(57.1)$ & $25(28.4)$ & $64(59.8)$ & \\
\hline$P$ values & $<0.001$ & & 0.004 & & 0.001 & & $<0.001$ & & \\
\hline OR $(95 \% \mathrm{Cl})$ & $2.977(1.6$ & 5.307) & $3.038(1.39$ & 635) & $2.783(1.45$ & 5.184) & $3.751(2.0$ & $6.857)$ & \\
\hline Marshall N (\% & & & & & & & & & \\
\hline$<2$ & 74 (79.6) & $104(94.5)$ & $136(86.6)$ & $37(90.2)$ & $66(93.0)$ & $96(83.5)$ & $81(89.0)$ & $91(85.8)$ & 39 \\
\hline$\geq 2$ & 19 (20.4) & $6(5.5)$ & $21(13.4)$ & $4(9.8)$ & $5(7.0)$ & $19(16.5)$ & $10(11.0)$ & $15(14.2)$ & \\
\hline$P$ values & 0.001 & & 0.543 & & 0.061 & & 0.506 & & \\
\hline OR $(95 \% \mathrm{Cl})$ & $4.450(1.6$ & 11.682) & $1.428(0.46$ & 419) & 2.613 & 7.345) & 1.335 & 3.137) & \\
\hline
\end{tabular}

APACHE Acute Physiology and Chronic Health Evaluation, ApoA-I apolipoprotein A-I, BISAP Bedside Index for Severity in Acute Pancreatitis, CRP C-reactive protein, $H D L-C$ high-density lipoprotein cholesterol

(67.0\% vs. $29.7 \%, \mathrm{OR}=4.801,95 \% \mathrm{CI}=2.771-8.318, P<$ 0.001 ) as compared to those patients with a high serum albumin (Table 6). Notably, low serum albumin was associated with all the clinical severity scoring parameters, including higher APACHE II, BISAP, Ranson and Marshall scores (all $P<0.05$, Table 6 ). In this study, there were 8 patients with BISAP scores $\geq 3$, who all presented with low serum albumin concentration.

\section{Discussion}

This study showed that low levels of albumin apoA-I and high levels of CRP and lipase upon admission were associated with the severity of HTGP and length of hospital stay, while none of the CT-based body composition parameters was linked to the severity of HTGP. Notably, low albumin concentration was also associated with pancreatic necrosis and all the severity scorings (APACHE II, BISAP, Ranson and Marshall) in patients with HTGP.
To our knowledge, this is the first study suggesting that low albumin and apoA-I, which are routinely tested in the clinic, may serve as risk factors for moderately severe to severe HTGP.

Albumin has been suggested as a predictive factor for the severity of AP [27]. In a recent study including 708 patients with AP and an additional 477 patients from validation cohort, reported that albumin was an independent predictor for SAP and in-hospital mortality in AP patients [28]. Albumin has also been incorporated into some panels for predicting severity of $\operatorname{AP}[29,30]$. Serum albumin together with extrapancreatic fluid collections were suggested as the best indicator of severity of AP at the time of admission [31]. Combining blood urea nitrogen and albumin resulted in better prediction for SAP in pediatric patients [32]. Besides, low albumin is also helpful to predict organ failure in AP [33]. It has been shown that low serum albumin is independently 
associated with an increased risk of persistent organ failure and death in AP [34].

However, the association of albumin concentration with the severity in HTGP, has not been investigated before. The current study found that HTGP patients with albumin $<35 \mathrm{~g} / \mathrm{L}$ had three times higher possibility to correlate with moderately severe or severe cases as compared to albumin $\geq 35 \mathrm{~g} / \mathrm{L}$. In HTGP, the deposition of free fatty acids hydrolyzed from TGs plays a crucial role in the mechanism of pancreatitis. Theoretically, a decrease of albumin, which can bind to the free fatty acids in the serum, may result in accumulation of free fatty acid, thus contributing to the inflammatory progression. Decrease of albumin may also be a consequence of the severe type of HTGP with higher amount of free fatty acid to be neutralized by albumin, and with increased vasopermeability allowing more albumin to permeate into the extravascular tissue space [35]. Besides, a decrease in albumin levels might also be relevant to the acute phase reaction due to the inflammatory response of HTGP.

Interestingly, this study showed that apoA-I alone achieved the highest AUC (0.786) to predict the severity of HTGP by ROC curves. With a balanced cutoff of 1.1 g/L, apoA-I predicted the severity of HTGP with a sensitivity and specificity of 0.725 and 0.784 , respectively. Furthermore, apoA-I was revealed as an independent predictor for the severity of HTGP with an OR of 5.126. ApoA-I and apoB are the main carrier proteins of HDL and non-HDL, respectively. The predictive role of lipid and lipoprotein parameters in the severity of AP and its subtype, HTGP, has drawn attention recently, due to their accessibility in the clinic. For instance, the ratio of apoB to apoA-I, and HDL-C/LDL-C have also been postulated to correlate with the severity of AP [36, 37]. Other studies showed that apoA-I and HDL-C were negatively associated with the severity of AP [38, 39]. In HTGP, it has also been reported that apoB was predictive for the occurrence of the disease in patients with HTG [40]. Besides, a recent study has showed that higher total cholesterol was indicative of the more severe type of HTGP and less efficiency of plasmapheresis [41]. To our knowledge, this study was the first to indicate the predictive role of apoA-I for the severity of HTGP. However, the underlying mechanism remain to be unveiled.

Although TGs level was not associated with the severity of HTGP in this study, which is in line with the study from $\mathrm{Yu}$ et al. [42], therapy that decrease the level of TGs less than $5.6 \mathrm{mmol} / \mathrm{L}$ is considered key to improve the outcome of HTGP. Insulin, heparin, and plasmapheresis are possible treatments to reduce serum TGs levels during the acute episode. To prevent the reoccurrence of HTGP, it is also crucial to keep the level of TGs consistently $<5.6 \mathrm{mmol} / \mathrm{L}$. Apart from the management of potential secondary factors that contribute to HTG, the treatment for HTG include weight loss, a very-low-fat diet, restricted carbohydrate and alcohol intake, fibrates, niacin and omega-3 fatty acids. Waylivra, an antisense oligo nucleotide inhibitor of apolipoprotein C- III, has recently been approved by the European Union for the treatment of FCS [6]. Besides, some new drugs targeting the TGs metabolism, including pemafibrate, AKCEA-APOCIII-LRX, AKCEA-ANGPTL3-LRX, ARO-APOC3 and ARO-ANGPTL3, have shown positive results in clinical trials $[6,9]$.

CRP and lipase levels upon admission were predictive for the severity of HTGP in this study. The result of the predictive role of CRP was consistent with the report from $\mathrm{Yu}$ and colleagues, in which 159 HTGP Chinese patients were retrospectively studied and high CRP and BMI were postulated as risk factors for severe HTGP [42]. CRP is one of the most widely utilized biomarkers in clinical practice for AP. CRP levels of $>150 \mathrm{mg} / \mathrm{L} 48 \mathrm{~h}$ after onset of symptoms have a high sensitivity for predicting severity of AP [43]. A rise of $>90 \mathrm{mg} / \mathrm{dL}$ from admission or an absolute value of $>190 \mathrm{mg} / \mathrm{dL}$ at $48 \mathrm{~h}$ predicted severe disease [44]. However, it is generally considered that the initial CRP value (at time of admission) is too early to be predictive for the severity of AP [45]. Lipase has been reported to be significantly higher in severe HTGP than in the non-severe group, although it failed to represent an independent factor for severity of HTGP [42].

The body composition parameters, especially VAT, have been reported to correlate with the severity of AP. Due to the involvement of lipoprotein metabolism in HTGP, this study also investigated whether body composition parameters were associated with the severity of HTGP. Intriguingly, no association was found between the severity of HTGP and any of these body composition parameters, including the CTmeasured muscle area, muscle radiodensity, SAT area/radiodensity, VAT area, and body mass index and waist circumference. In comparison, VAT area was reported to correlate with the severity of HTGP [23]. Several factors may contribute to the discrepancy. Firstly, the present study noticed that gender has a significant impact on all body composition parameters evaluated, in line with previous reports [46]. Therefore, the cut-off level of each body composition parameter and the subsequent statistical analysis were gender dependent in the present study. Secondly, the present study included HTGP with any severity, while the previous study only included moderately severe to severe patients from the intensive care unit [23]. Lastly, there is a difference of sample size between the two studies. 
Pancreatic necrosis is a parameter for CT-based evaluation of the severity of AP, and is closely associated with morbidity and mortality in AP [47]. The management of pancreatic necrosis has been highlighted due to its significance for the outcome of AP [48]. The association between body composition and mortality in AP with pancreatic necrosis has been investigated, concluding that loss of skeletal muscle density within the first month after initial admission was significantly associated with increased mortality [49]. It has been shown that patients with HTGP had a higher incidence of pancreatic necrosis as compared to AP with other etiologies [50]. In HTGP, excess TGs are hydrolyzed by lipase from pancreatic acinar cells to produce FFAs, which in turn cause acinar necrosis [3]. This study suggested that low serum albumin and LDL-C and high SAT radiodensity were associated with pancreatic necrosis in patients with HTGP.

\section{Study strengths and limitations}

This study, which enrolled 242 patients with HTGP, for the first time revealed that albumin and apoA-I, may serve as novel biomarkers for the severity of HTGP. There are several limitations of the study. Firstly, this study was carried out retrospectively. Although there was an auto-dilution procedure of blood samples before chemical analysis with a routine method in the clinic, HTG may have impact on the determination of other laboratory parameters. Secondly, this study was not able to investigate the causes of HTG in patients, including the proportion of FCS.

\section{Conclusions}

This study showed that low levels of albumin and apoAI, as well as high levels of CRP and lipase upon admission, were associated with the severity of HTGP and the length of hospital stay. Albumin and apoA-I may serve as novel biomarkers for the severity of HTGP. Besides, HTGP patients with low albumin should be kept under close surveillance during the disease progression. Prospective validation of the predictive role of albumin and apoA-I for the severity of HTGP are needed before translating the finding to clinical practice.

\footnotetext{
Abbreviations

AP: Acute pancreatitis; APACHE: Acute Physiology and Chronic Health Evaluation; ApoA-l: Apolipoprotein A-l; ApoB: Apolipoprotein B; AUC: Areas under the curves; BISAP: Bedside Index for Severity in Acute Pancreatitis; BMI: Body mass index; Cl: Confidence interval; CRP: C-reactive protein; $\mathrm{CT}$ : Computed tomography; FCS: Familial chylomicronemia syndrome; HDLC: High-density lipoprotein cholesterol; HTG: Hypertriglyceridemia; HTGP: Hypertriglyceridemia-induced pancreatitis; HU: Hounsfield units; LDLC: Low-density lipoprotein cholesterol; MCTSI: Modified CT severity index; OR: Odds ratio; ROC: Receiver operating characteristic; SAT: Subcutaneous adipose tissue; TAT: Total adipose tissue; TG: Triglyceride; VAT: Visceral adipose tissue
}

\section{Acknowledgements}

We thank Prof. Roland Andersson for the language editing.

\section{Authors' contributions}

Chen $L$ performed the experiments, analyzed the data and wrote the initial draft of the manuscript; Huang YB analyzed the data and assisted in manuscript writing and study conception; Yu HJ collected the clinical data and follow-up of the patients; Pan KH, Zhang Z and Man Y critically revised the manuscript for important intellectual content; Hu DY conceived the study; all authors read and approved the final manuscript.

\section{Funding}

This work was supported by a grant from the Public Welfare Science and Technology Plan Project of Wenzhou City (Y20170829, Y20170062,

\section{Y2020282).}

\section{Availability of data and materials}

All relevant data and materials are included in the manuscript. For the full detailed data, please contact the corresponding author.

\section{Ethics approval and consent to participate}

The study protocol was approved by the ethics committee of the First Affiliated Hospital of Wenzhou Medical University (KY2019-011). Participant informed consent was waived given the retrospective study design.

\section{Consent for publication}

Not applicable.

\section{Competing interests}

The authors declare no conflicts of interest.

\section{Author details}

${ }^{1}$ Department of Radiology, the First Affiliated Hospital of Wenzhou Medical University, Wenzhou, China. ${ }^{2}$ The Center of Diagnosis and Treatment of Pancreatitis, the First Affiliated Hospital of Wenzhou Medical University, Wenzhou, China. ${ }^{3}$ Department of Gastroenterology, the Second Affiliated Hospital of Wenzhou Medical University, Xue Yuan Xi Lu 109, Lucheng District, Wenzhou 325027, China.

Received: 18 December 2020 Accepted: 3 February 2021 Published online: 11 February 2021

\section{References}

1. Jin M, Bai X, Chen X, Zhang H, Lu B, Li Y, et al. A 16-year trend of etiology in acute pancreatitis: the increasing proportion of hypertriglyceridemiaassociated acute pancreatitis and its adverse effect on prognosis. J Clin Lipidol. 2019;13:947-53 e1.

2. Pothoulakis I, Paragomi P, Archibugi L, Tuft M, Talukdar R, Kochhar R, et al. Clinical features of hypertriglyceridemia-induced acute pancreatitis in an international, multicenter, prospective cohort (APPRENTICE consortium). Pancreatology. 2020;20:325-30.

3. Yang AL, McNabb-Baltar J. Hypertriglyceridemia and acute pancreatitis. Pancreatology. 2020;20:795-800.

4. Carr RA, Rejowski BJ, Cote GA, Pitt HA, Zyromski NJ. Systematic review of hypertriglyceridemia-induced acute pancreatitis: a more virulent etiology? Pancreatology. 2016;16:469-76.

5. Rawla P, Sunkara T, Thandra KC, Gaduputi V. Hypertriglyceridemia-induced pancreatitis: updated review of current treatment and preventive strategies. Clin J Gastroenterol. 2018;11:441-8.

6. Wolska A, Yang ZH, Remaley AT. Hypertriglyceridemia: new approaches in management and treatment. Curr Opin Lipidol. 2020;31:331-9.

7. Grundy SM, Stone NJ, Bailey AL, Beam C, Birtcher KK, Blumenthal RS, et al. 2018 AHA/ACC/AACVPR/AAPA/ABC/ACPM/ADA/AGS/APhA/ASPC/NLA/ PCNA guideline on the Management of Blood Cholesterol: a report of the American College of Cardiology/American Heart Association task force on clinical practice guidelines. Circulation. 2019;139:e1082-143.

8. Jacobsen A, Savji N, Blumenthal RS, Martin SS. Hypertriglyceridemia Management According to the 2018 AHA/ACC Guideline. Expert Analysis. 2019; https:/www.acc.org/latest-in-cardiology/articles/2019/01/11/07/39/ hypertriglyceridemia-management-according-to-the-2018-aha-acc-guideline. Accessed 25 Jan 2021. 
9. Laufs U, Parhofer KG, Ginsberg HN, Hegele RA. Clinical review on triglycerides. Eur Heart J. 2020;41:99-109C.

10. Stroes E, Moulin P, Parhofer KG, Rebours V, Löhr JM, Averna M. Diagnostic algorithm for familial chylomicronemia syndrome. Atheroscler Suppl. 2017 23:1-7.

11. Havel RJ. Pathogenesis, differentiation and management of hypertriglyceridemia. Adv Intern Med. 1969;15:117-54.

12. Working Group IAPAPAAPG. IAP/APA evidence-based guidelines for the management of acute pancreatitis. Pancreatology. 2013;13:e1-15.

13. Tenner S, Baillie J, DeWitt J, Vege SS. American College of Gastroenterology guideline: management of acute pancreatitis. Am J Gastroenterol. 2013;108: 1400-15.

14. Funnell IC, Bornman PC, Weakley SP, Terblanche J, Marks IN. Obesity: an important prognostic factor in acute pancreatitis. Br J Surg. 1993;80:484-6.

15. Li M, Xing X-K, Lu Z-H, Guo F, Su W, Lin Y-J, et al. Comparison of Scoring Systems in Predicting Severity and Prognosis of HypertriglyceridemiaInduced Acute Pancreatitis. Digestive Diseases and Sciences. 2019;65:120611.

16. Di MY, Liu H, Yang ZY, Bonis PA, Tang JL, Lau J. Prediction models of mortality in acute pancreatitis in adults: a systematic review. Ann Intern Med. 2016;165:482-90.

17. Bollen TL, Singh VK, Maurer R, Repas K, van Es HW, Banks PA, et al. A comparative evaluation of radiologic and clinical scoring systems in the early prediction of severity in acute pancreatitis. Am J Gastroenterol. 2012; 107:612-9.

18. Xie J, Xu L, Pan Y, Li P, Liu Y, Pan Y, et al. Impact of visceral adiposity on severity of acute pancreatitis: a propensity score-matched analysis. BMC Gastroenterol. 2019;19:87.

19. Yashima $Y$, Isayama H, Tsujino T, Nagano R, Yamamoto K, Mizuno S, et al. A large volume of visceral adipose tissue leads to severe acute pancreatitis. J Gastroenterol. 2011;46:1213-8.

20. Yoon SB, Choi MH, Lee IS, Lim CH, Kim JS, Cho YK, et al. Impact of body fat and muscle distribution on severity of acute pancreatitis. Pancreatology. 2017;17:188-93.

21. Kuan LL, Dennison AR, Garcea G. Association of visceral adipose tissue on the incidence and severity of acute pancreatitis: a systematic review. Pancreatology. 2020;20:1056-61.

22. Sternby H, Mahle M, Linder N, Erichson-Kirst L, Verdonk RC, Dimova A, et al. Mean muscle attenuation correlates with severe acute pancreatitis unlike visceral adipose tissue and subcutaneous adipose tissue. United European Gastroenterol J. 2019;7:1312-20.

23. Ji T, Li X, Zhang X, Hui L, Shang F, Zhu X, et al. Evaluation of the severity of hyperlipidemia pancreatitis using CT-measured visceral adipose tissue. J Clin Gastroenterol. 2019:53:e276-e83.

24. Banks PA, Bollen TL, Dervenis C, Gooszen HG, Johnson CD, Sarr MG, et al. Classification of acute pancreatitis--2012: revision of the Atlanta classification and definitions by international consensus. Gut. 2013;62:102-11.

25. Berglund L, Brunzell JD, Goldberg AC, Goldberg IJ, Sacks F, Murad MH, et al. Evaluation and treatment of hypertriglyceridemia: an Endocrine Society clinical practice guideline. J Clin Endocrinol Metab. 2012;97:2969-89.

26. Girish V, Vijayalakshmi A. Affordable image analysis using NIH image/lmageJ. Indian J Cancer. 2004;41:47.

27. Holliday MP, Shaw D, Thomas WM, Leese T. Threshold for albumin as a prognostic marker in acute pancreatitis. Br J Surg. 1989;76:472-3.

28. Xu X, Ai F, Huang M. Deceased serum bilirubin and albumin levels in the assessment of severity and mortality in patients with acute pancreatitis. Int J Med Sci. 2020;17:2685-95.

29. Hong W, Lillemoe KD, Pan S, Zimmer V, Kontopantelis E, Stock S, et al. Development and validation of a risk prediction score for severe acute pancreatitis. J Transl Med. 2019;17:146.

30. Szabo FK, Hornung L, Oparaji JA, Alhosh R, Husain SZ, Liu QY, et al. A prognostic tool to predict severe acute pancreatitis in pediatrics. Pancreatology. 2016;16:358-64

31. Robert JH, Frossard JL, Mermillod B, Soravia C, Mensi N, Roth M, et al. Early prediction of acute pancreatitis: prospective study comparing computed tomography scans, Ranson, Glascow, acute physiology and chronic health evaluation II scores, and various serum markers. World J Surg. 2002;26:6129.

32. Farrell PR, Hornung L, Farmer P, DesPain AW, Kim E, Pearman R, et al. Who's at risk? A prognostic model for severity prediction in pediatric acute pancreatitis. J Pediatr Gastroenterol Nutr. 2020;71:536-42.
33. Wu H, Li J, Zhao J, Li S. A new scoring system can be applied to predict the organ failure related events in acute pancreatitis accurately and rapidly. Pancreatology. 2020;20:622-8.

34. Hong W, Lin S, Zippi M, Geng W, Stock S, Basharat Z, et al. Serum albumin is independently associated with persistent organ failure in acute pancreatitis. Can J Gastroenterol Hepatol. 2017;2017:5297143.

35. Arroyo V, Garcia-Martinez R, Salvatella X. Human serum albumin, systemic inflammation, and cirrhosis. J Hepatol. 2014;61:396-407.

36. Huh JH, Jung S, Cho SK, Lee KJ, Kim JW. Predictive value of apolipoprotein $B$ and $A-I$ ratio in severe acute pancreatitis. J Gastroenterol Hepatol. 2018;33: 548-53.

37. Wu Q, Zhong X, Fu M, Yang H, Bo H, Liao X, et al. High-density lipoprotein cholesterol to low-density lipoprotein cholesterol ratio in early assessment of disease severity and outcome in patients with acute pancreatitis admitted to the ICU. BMC Gastroenterol. 2020;20:164

38. Zhou CL, Zhang CH, Zhao XY, Chen $\mathrm{SH}$, Liang HJ, Hu CL, et al. Early prediction of persistent organ failure by serum apolipoprotein $\mathrm{A}-\mathrm{I}$ and highdensity lipoprotein cholesterol in patients with acute pancreatitis. Clin Chim Acta. 2018;476:139-45.

39. Peng YS, Chen YC, Tian YC, Yang CW, Lien JM, Fang JT, et al. Serum levels of apolipoprotein $\mathrm{A}-\mathrm{I}$ and high-density lipoprotein can predict organ failure in acute pancreatitis. Crit Care. 2015;19:88.

40. Gonzales KM, Donato LJ, Shah P, Simha V. Measurement of apolipoprotein B levels helps in the identification of patients at risk for hypertriglyceridemic pancreatitis. J Clin Lipidol. 2020:S1933-2874(20)30336-6. https://doi.org/10.1 016/j.jacl.2020.11.010 Epub ahead of print. PMID: 33328149

41. Chen Z, Huang X, Han N, Guo Y, Chen J, Ning Y, et al. Total cholesterol concentration predicts the effect of plasmapheresis on hypertriglyceridemic acute pancreatitis: a retrospective case-control study. BMC Gastroenterol. 2021;21:3.

42. Yu S, Wu D, Jin K, Yin L, Fu Y, Liu D, et al. Low serum ionized calcium, elevated high-sensitivity C-reactive protein, neutrophil-lymphocyte ratio, and body mass index (BMI) are risk factors for severe acute pancreatitis in patients with hypertriglyceridemia pancreatitis. Med Sci Monit. 2019;25: 6097-103.

43. Dervenis C. Assessments of severity and management of acute pancreatitis based on the Santorini consensus conference report. JOP. 2000;1:178-82.

44. Stirling AD, Moran NR, Kelly ME, Ridgway PF, Conlon KC. The predictive value of $C$-reactive protein (CRP) in acute pancreatitis - is interval change in CRP an additional indicator of severity? HPB (Oxford). 2017;19:874-80.

45. Mofidi R, Patil PV, Suttie SA, Parks RW. Risk assessment in acute pancreatitis. Br J Surg. 2009;96:137-50.

46. Xiao J, Caan BJ, Cespedes Feliciano EM, Meyerhardt JA, Peng PD, Baracos VE, et al. Association of low Muscle Mass and low Muscle Radiodensity with Morbidity and mortality for Colon Cancer surgery. JAMA Surg. 2020;155: 942-9.

47. Trikudanathan G, Wolbrink DRJ, van Santvoort HC, Mallery S, Freeman M, Besselink MG. Current concepts in severe acute and necrotizing pancreatitis: an evidence-based approach. Gastroenterology. 2019;156:1994-2007 e3.

48. Baron TH, DiMaio CJ, Wang AY, Morgan KA. American Gastroenterological Association Clinical Practice Update: Management of Pancreatic Necrosis. Gastroenterology. 2020;158:67-75.e1.

49. van Grinsven J, van Vugt JLA, Gharbharan A, Bollen TL, Besselink MG, van Santvoort HC, et al. The Association of Computed Tomography-Assessed Body Composition with mortality in patients with necrotizing pancreatitis. J Gastrointest Surg. 2017;21:1000-8.

50. He WH, Zhu Y, Zhu Y, Liu P, Zeng H, Xia L, et al. Comparison of severity and clinical outcomes between hypertriglyceridemic pancreatitis and acute pancreatitis due to other causes. Zhonghua Yi Xue Za Zhi. 2016;96:2569-72.

\section{Publisher's Note}

Springer Nature remains neutral with regard to jurisdictional claims in published maps and institutional affiliations. 